\title{
Gender comparison of clinical outcomes post high-flex total knee arthroplasty.
}

\author{
Hui Peng, Shenglin Lu, Yu Bai, Xu Fang, Hui Huang, Xiaoqiang Zhuang* \\ Department of Orthopaedics, the Affiliated National Hospital of Guangxi Medical University, Nanning, Guangxi, PR China
}

\begin{abstract}
Background: Although it is normally perceived that knee morphometry contrasts exist amongst the female as well as male populations, the literature normally disproves the need for gender specific totalknee prosthesis clinically. It was noted that standard/unisex knee performs alike or better in female than male. As of late, high flex knees became accessible, that mechanically accommodate raised flexion but not many studies have contrasted these devices' results in male and female to find out if there is any gender based contrast.

Methods and results: We aimed to compare midterm functional outcomes as well as survivorship of large cohorts of male and female acquiring Cruciate Retaining (CR) high flex knee in 744 females (994 knees) and 469 males (641 knees). Kaplan Meier survival analysis was similar in genders, i.e., $97.5 \%$ (95\% CI: 96.7-98.9\%) at 5.8 y for males and 97.5\% (95\% CI: 95.9-99.2\%) at 5.9 y for females. Mean improvement in Knee Society score (KSS) Knee and KSS Function for male and female (51.2 vs. 45.3; 26.7 vs. 22.8) and Short Form Health Survey (SF12) Mental as well as Physical scores (0.3 vs. 2.3; 14.2 vs. 13.2) were identical with contrasts irrelevant clinically.

Conclusion: During stratification of motion results by preoperative values, we discovered nearly similar differences between preop and postop Range of Motion (ROM) as well as Peak Flexion (PF) values for both male and female. This demonstrates that a specific high flex knee configuration had similar clinical efficacy in both genders.
\end{abstract}

Keywords: Gender specific, Total knee arthroplasty, Outcomes.

Accepted on December 1, 2017

\section{Introduction}

Knee morphometry contrasts exist amongst female as well as male populations. Such contrasts include small size, large Q angle, small Medial-Lateral (ML) to Anterio-Posterior (AP) femoral condyle aspect ratio, small anterior condyle observable prominence, and slender patella in female knees compared to male knees [1-6]. This has prompted to the prospect that standard total-knee implants in female might tend to overstuff the patellofemoral compartment prompting to a lessened motion range and enhanced overhang with resulting lateral as well as medial knee pain, because of soft tissue irritation. Gender specific knee outlines seek to address these worries via design alterations, to accommodate the female femoral condyle better, like altering anterior flange to incorporate recess sulcus and lessened anterior condyle height, decreasing the ML and AP aspect ratio, and expanding trochlear groove angle etc. $[3,7]$. The greatly contemplated gender specific knee system is Zimmer Gender Solutions NexGen Knee (Zimmer Inc., Warsaw, IN). Such examinations comprised unilateral as well as bilateral studies in female and Indian as well as Tai patients [8-14]. Although, the available literature, supports a little of gender specific prostheses. A systematic review by Merchant et al. summarized that the evident anatomic contrasts amongst the female as well as male knee were because of small size and height of female but not of gender, essentially [15].

Meta-analysis by Xie et al. additionally found no proof to base the requirement for gender specific knees [7]. Despite the studies demonstrating their results to be comparable between the genders with standard knees [15-19], it has additionally been demonstrated that results are not significantly different in female whether they get a standard or a gender specific knee $[8,10-13]$.

As of late, high flex knees [20-22], which could mechanically accommodate even $125^{\circ}$ of flexion (ASTM F2083) became popular; although, their capacity to support males and females alike was not set up. Just a single little intraoperative review (40 patients) and a few small ( $<50$ patients) or intermediate cohort (138 patients) [8-13] studies have contrasted high flex knee with gender specific knee, demonstrating no clear benefit with one over another.

The aim of present study was the comparison of midterm functional outcomes as well as survivorship of large cohorts of male and female acquiring Cruciate Retaining (CR) high flex knee. We hypothesized that there would be no gender difference in those measurements. 


\section{Methods}

From August 2005 to March 2014, overall 1,213 patients received 1,635 CR knees (744 females (994 knees) and 469 males (641 knees)) of such kind via medial para patellar approach utilizing cemented fixation. The high flex Vanguard knee (Biomet, IN) was used that could accommodate nearly $145^{\circ}$ flexion, even though clinical achievement might be less because of patient's soft tissue restraint $[20,23]$. All the patella was resurfaced. Till 2011, standard overlay templating was utilized for determination of appropriate implant size, and later digital templating was used. There were 10 Femoral Component (FC) nominal sizes, i.e., 55 to 75 in 2.5 increments, plus 80, as well as 9 Tibia Component (TC) nominal sizes, i.e., 59 to 91 in 4 increments in present system. All respective sizes have compatibility with each other alongside their respective ranges. The TC was sized for best fit on the cut surface, with no AP or ML overhang. The FC was sized utilizing posterior referencing femoral size, which was a part of the framework. All surgeries were conducted by senior author post the Institutional ethics committee approval was acquired for the present study, and patient confidentiality was strictly maintained. Mean follow up for female and male patients was noted to be $2.4 \mathrm{y}$ (range; 0.8-7.3 y) and $2.4 \mathrm{y}$ (range: 0.9-6.8 y), respectively.

Kaplan Meier survival analysis was conducted for both genders (641 male and 994 female knees), with 95\% confidence interval $(95 \% \mathrm{CI})$, with any component revision for any reason as endpoint. Final survival intervals were selected to be comparable to those, where 20 knees stayed at-risk to overcome the uncertainty that could result when the rest of the population turns out to be too little [24]. The final interim was $5.7 \mathrm{y}$ for males and $5.8 \mathrm{y}$ for females.

Functional analysis was conducted just on knees with at least 2 $\mathrm{y}$ of full clinical follow up. Clinical evaluation comprised of preop and final postop Knee Society Score (KSS) [25] and SF 12 [26]. Two hundred and eighty-three male patients (377 knees) and 433 female patients (552 knees) had full preop and at least $2 \mathrm{y}$ of full clinical follow up, with mean last follow up of $2.8 \mathrm{y}$ (range; 1.9-6.8 y) and $2.8 \mathrm{y}$ (range; 2.0-7.2 y), respectively. Preop and $\geq 2$ y postop passive Range of Motion (ROM) as well as passive Peak Flexion (PF) information was accessible for 432 male knees as well as 649 female knees. Motion outcomes were stratified by preop motion range, i.e, $<$ $95^{\circ}, 95-105^{\circ}$, and $>105^{\circ}$.

Means of interval data between genders (patient age, length of stay/follow up, body mass index, KSS, SF12, PF, and ROM) were contrasted utilizing pooled -test. Paired -test was utilized for comparison of preop to postop outcome changes, as per gender. Chi-square test was utilized for comparison of nominal data mean differences (right knee proportion and primary diagnosis distribution). An estimate of $<0.05$ was selected for statistical significance.

\section{Results}

The clinical/demographic characteristics of total number of patients along with those who have completed at least $2 \mathrm{y}$ of follow up are presented in Table 1. There was no significant difference observed with respect to gender in diagnosis $(p=0.359)$, right knee proportion $(p=0.372)$, or follow up $(p=0.983)$. Although, significant difference in age $(p=0.022)$, length of stay $(p<0.001)$, and body mass index $(p=0.007)$ for males vs. females was noted. Overall, 32 patients died due to unassociated knee procedure reasons (11 men (15 knees) and 13 women (17 knees)), with all implants set up during death.

Outcome summaries of SF-12 and KSS were mentioned in Table 2. Both male and female had comparable SF12 physical scores whereas female had higher KSS Knee scores and male had higher KSS function as well as SF12 mental scores. Postoperatively, male and female had comparable KSS Knee scores, whereas male had higher KSS Function as well as SF12 (all two components) scores. Significant preoperative to postoperative rise $(\mathrm{p}<0.0001)$ in all KSS and SF12 components was observed in both male and female, except SF12 Mental score in male.

Preop and postop score change comparisons $\left(\Delta_{\text {scores }}\right)$ for men and women were listed in Table 3. Significantly higher KSS knee/function and SF12 physical $\Delta_{\text {scores }}$ was noted in case of men and higher SF12 mental $\Delta_{\text {scores }}$ were noted in case of women.

Stratification of ROM and PF outcomes of men and women was mentioned in Tables 4 and 5, respectively, by preoperative motion with two apparent principal observations. To start with, the motion $\left(\Delta_{\mathrm{ROM}}\right.$ and $\left.\Delta_{\mathrm{PF}}\right)$ improvement was inversely proportional to the preoperative motion, i.e., knees having less movement before surgery tended to accomplish a more noteworthy increment post-surgery, than did knees at first giving a high level of movement. Secondly, there were no significant contrasts in preop to postop motion change between genders, except for a $2.7^{\circ} \mathrm{PF}$ difference for men. The similar proportion of male as well as female knees (82-84\%) accomplished $\geq 120^{\circ}$ of $\mathrm{ROM} / \mathrm{PF}$, with no significant contrasts between genders (ROM: $\mathrm{p}=0.735$; PF: $\mathrm{p}=0.324$ ).

An aggregate of 8 amendments were done including 5 male knees at $0.68 \mathrm{y}$ (infection), $0.76 \mathrm{y}$ (aseptic loosening), $1.6 \mathrm{y}$ (infection), $2.3 \mathrm{y}$ (infection), and $2.43 \mathrm{y}$ (aseptic loosening), and 3 female knees at $2.46 \mathrm{y}$ (aseptic loosening), $4.28 \mathrm{y}$ (infection), and $5.35 \mathrm{y}$ (dislocation). All segments were replaced in five corrections, just the tibia segment and liner in two amendments, and the femoral/tibial/liner in one amendment. Kaplan Meier survival analysis was similar in genders, i.e., $97.5 \%$ (95\% CI: 96.7-98.9\%) at $5.8 \mathrm{y}$ for males and $97.5 \%$ (95\% CI: $95.9-99.2 \%)$ at 5.9 y for females.

Table 1. Clinical/demographic characteristics. 


\begin{tabular}{|c|c|c|c|c|}
\hline \multirow[t]{2}{*}{ Characteristics } & \multicolumn{2}{|l|}{ Total } & \multicolumn{2}{|c|}{ Complete $\geq 2$ y follow up } \\
\hline & Female & Male & Female & Male \\
\hline No. of patients & 744 & 469 & 433 & 283 \\
\hline No. of knees & 994 & 641 & 552 & 377 \\
\hline Right knee proportion & $52.60 \%$ & $50.40 \%$ & $51.60 \%$ & $50.40 \%$ \\
\hline Age $(y)^{*}$ & $71.8(38-94)$ & $70.7(43-95)$ & $70.8(38-94)$ & $70.8(38-94)$ \\
\hline Body mass index $\left(\mathrm{kg} / \mathrm{m}^{2}\right)^{*}$ & $32.9(18-75)$ & $31.8(8-78)$ & $32.9(18-75)$ & $32.9(18-75)$ \\
\hline \multicolumn{5}{|l|}{ Diagnosis } \\
\hline OA & $97.40 \%$ & $98.40 \%$ & $97.20 \%$ & $98.50 \%$ \\
\hline RA & $1.50 \%$ & $0.90 \%$ & $1.80 \%$ & $1.10 \%$ \\
\hline AN & $0.70 \%$ & $0.40 \%$ & $0.60 \%$ & $0.40 \%$ \\
\hline ON & $0.20 \%$ & $0 \%$ & $0.20 \%$ & $0 \%$ \\
\hline PA & $0.10 \%$ & $0.10 \%$ & $0.20 \%$ & $0 \%$ \\
\hline Others & $0.10 \%$ & $0.20 \%$ & $0 \%$ & $0 \%$ \\
\hline Length of stay $(d)^{*}$ & $2.4(1.1-19)$ & $2.3(1-23)$ & $2.4(1.2-11)$ & $2.2(1-12)$ \\
\hline Follow up $(y)^{*}$ & $2.5(0.9-7.4)$ & $2.5(0.9-7.2)$ & $2.8(1.9-7.3)$ & $2.8(1.9-7.1)$ \\
\hline
\end{tabular}

AN: Avascular Necrosis; OA: Osteoarthritis; ON: Osteonecrosis; PA: Posttraumatic Arthritis; RA: Rheumatois Arthritis. *Values are expressed as mean with range, if not mentioned otherwise.

Table 2. Outcome summaries of SF-12 and knee society score post $\geq 2$ y.

\begin{tabular}{|c|c|c|c|c|c|c|}
\hline \multirow[t]{2}{*}{ Component } & \multicolumn{3}{|l|}{ Female } & \multicolumn{3}{|l|}{ Male } \\
\hline & Preop & Postop & $P$ value & Preop & Postop & $P$ value \\
\hline \multicolumn{7}{|l|}{ KSS } \\
\hline Knee & $42.5(0-100)^{a}$ & $88.9(24-100)^{\mathrm{e}}$ & $<0.0001$ & $41.2(0-94)^{a}$ & $92.2(34-100)^{\mathrm{e}}$ & $<0.0001$ \\
\hline Function & $52.2(0-100)^{b}$ & $73.5(0-100)^{f}$ & $<0.0001$ & $59.6(6-100)^{b}$ & $85.2(18-100)^{f}$ & $<0.0001$ \\
\hline \multicolumn{7}{|l|}{ SF12 } \\
\hline Physical & $31.8(12.8-57.2)^{\mathrm{c}}$ & $42.8(7.8-64.0)^{\mathrm{g}}$ & $<0.0001$ & $32.5(12.4-57.4)^{\mathrm{c}}$ & $45.4(14.6-64.8)^{9}$ & $<0.0001$ \\
\hline Mental & $52.4(14.2-76.8)^{d}$ & $53.8(25.8-71)^{\mathrm{h}}$ & $<0.0001$ & $54.4(22.2-76.2)^{d}$ & $55.8(31.8-72.4)^{\mathrm{h}}$ & 0.732 \\
\hline
\end{tabular}

Values are expressed as mean with range, if not mentioned otherwise. $P$ values for intra preop/intra postop comparisons: ${ }^{a} 0.0061,{ }^{b}<0.0001,{ }^{c} 0.261,{ }^{d}<0.0001,{ }^{e} 0.128$, $\mathrm{f}_{<} 0.0001,90.0025$, and ${ }^{\mathrm{h}} 0.0034$.

Table 3. Preop and postop score change comparison $\left(\Delta_{\text {scores }}\right)$.

\begin{tabular}{llll}
\hline Score & \multicolumn{1}{c}{$\boldsymbol{\Delta}_{\text {scores }}$} & P value \\
\cline { 2 - 3 } & $\mathbf{F}(\mathbf{n}=\mathbf{5 5 2})$ & $\mathbf{M}(\mathbf{n}=\mathbf{3 7 7})$ & \\
\cline { 1 - 2 } KSS & & \\
\hline Knee & $45.3 \pm 21.8$ & $51.2 \pm 22.1$ & 0.007 \\
\hline Function & $22.8 \pm 24.9$ & $26.7 \pm 20.4$ & 0.015 \\
\hline
\end{tabular}

\begin{tabular}{lccc}
\hline SF12 & & & \\
\hline Physical & $13.2 \pm 11.8$ & $14.2 \pm 11.5$ & 0.004 \\
\hline Mental & $2.3 \pm 11.4$ & $0.3 \pm 11.1$ & 0.027 \\
\hline
\end{tabular}

Values are expressed as average with standard deviation, if not mentioned otherwise.

Table 4. ROM comparisons post $\geq 2 y$. 


\begin{tabular}{|c|c|c|c|c|c|}
\hline \multirow[t]{2}{*}{ Preop ROM } & \multicolumn{2}{|l|}{ Female } & \multicolumn{3}{|l|}{ Male } \\
\hline & Postop ROM ( ${ }^{\circ}$ ) & $\Delta \operatorname{ROM}\left({ }^{\circ}\right)^{\mathrm{a}}$ & Postop ROM ( $\left.{ }^{\circ}\right)$ & $\Delta \operatorname{ROM}\left({ }^{\circ}\right)^{\mathrm{a}}$ & $P$ value $^{b}$ \\
\hline$<95^{\circ}$ & $112.8 \pm 11.0(n=68)$ & $33.2 \pm 10.0(n=68)$ & $116.4 \pm 7.9(n=42)$ & $31.8 \pm 8.4(n=42)$ & 0.457 \\
\hline $95^{\circ}-105^{\circ}$ & $117.9 \pm 4.3(n=186)$ & $16.5 \pm 5.6(n=186)$ & $118.3 \pm 4.4(n=121)$ & $17.7 \pm 5.8(n=121)$ & 0.526 \\
\hline$>105^{\circ}$ & $118.6 \pm 5.2(n=372)$ & $3.4 \pm 6.5(n=372)$ & $119.8 \pm 5.6(n=256)$ & $3.9 \pm 7.9(n=256)$ & 0.282 \\
\hline
\end{tabular}

ROM: Range of Motion. Values are expressed as mean with standard deviation, if not mentioned otherwise. a ${ }^{\mathrm{R}} \mathrm{RM}_{\mathrm{M}}$ is paired difference of preop as well as postop ROM. bMale vs. ${ }^{\text {afemale }} \Delta_{\text {ROM }}$

Table 5. PF comparisons post $\geq 2$.

\begin{tabular}{|c|c|c|c|c|c|}
\hline \multirow[t]{2}{*}{ Preop PF } & \multicolumn{2}{|l|}{ Female } & \multicolumn{3}{|l|}{ Male } \\
\hline & Postop PF $\left(^{\circ}\right)$ & $\Delta \mathrm{PF}\left({ }^{\circ}\right) \mathrm{a}$ & Postop PF $\left(^{\circ}\right)$ & $\Delta \mathrm{PF}\left({ }^{\circ}\right) \mathrm{a}$ & $P$ value ${ }^{b}$ \\
\hline$<95^{\circ}$ & $110.9 \pm 12.8(n=24)$ & $23.6 \pm 11.8(n=24)$ & $109.8 \pm 12.9(n=8)$ & $24.1 \pm 9.4(n=8)$ & 0.879 \\
\hline $95^{\circ}-105^{\circ}$ & $116.2 \pm 5.2(n=61)$ & $14.9 \pm 5.5(n=61)$ & $118.1 \pm 4.2(n=39)$ & $17.6 \pm 5.8(n=39)$ & $0.039 c$ \\
\hline$>105^{\circ}$ & $118.8 \pm 4.2(n=541)$ & $3.6 \pm 6.3(n=541)$ & $119.9 \pm 4.8(n=372)$ & $3.8 \pm 6.5(n=372)$ & 1 \\
\hline
\end{tabular}

PF: Peak Flexion. Values are expressed as mean with standard deviation, if not mentioned otherwise. ${ }^{\text {a }} \Delta_{\mathrm{PF}}$ is paired difference of preop as well as postop PF. ${ }^{b}$ Male $v s$. female $a \Delta_{P F}{ }^{c}$ Significant.

\section{Discussion}

The minute uncertainty in knee morphometry contrasts has prompted to the theory that standard/unisex knees devised irrespective of sexual orientation contrasts could deliver mediocre results in females, and that a gender specific knee might be needed to address the issue [1-7,27]. Meta-analysis as well as systematic reviews of literature, though, advices the inverse; i.e., females get equivalent, if not best, results than males utilizing standard knees [7,15]. Different studies that contrasted 8,700 women knees with 5,927 men knees, both given standard implants, arrived at a similar conclusion. As of late, high-flex knees have been created to give expanded flexion potential, which is particularly helpful for high demand patients $[16,19,20-22]$. It might be possible that gender related contrasts in results may get to be distinctly shown with the utilization of such superior prostheses, because such devices can potentially strengthen the impact of knee morphology on performance clinically.

Four reviews altogether analysed 308 bilateral women patients, having one knee supplanted with a gender specific high flex knee whereas another knee getting a unisex one (high or nonhigh flex) [10-13]. Although, there was no evident advantage of gender specific high flex design in females, these reviews did not specifically address the requirement for gender specific high flex knees because no males were included, with whom the result comparison can be made. The present study compared the utilization of a unisex high-flex knee in both genders. The high flex CR knee utilized for addressing the issue was selected, to some degree, because there has been big cohort, mid-term studies published recently on present framework to give a standard to which our outcomes might be analysed [20,28].
In our review, the aggregate population of 1,635 high flex CR knees brought about just eight amendments. Stratifying survival by gender yielded Kaplan Meier survival analysis estimates of $97.5 \%$ for both males and females at $5.8 \mathrm{y}$ and 5.9 y, respectively. A study by Shroer et al. showed comparative Kaplan Meier survival for similar knee, i.e., $97.8 \%$ at 7 y [20]. Studies by Kievit et al. and Nassif et al. reported $98.6 \%$ at $6 \mathrm{y}$ and $98.5 \%$ at $5.6 \mathrm{y}$, respectively $[28,29]$.

Except for the KSS Knee score, the preop state of male knees was superior to that of female knees significantly $(\mathrm{p}<0.05)$ for all, except SF12 physical component. Reports of other studies showed comparable discoveries likely because female tend to present for surgery later, with lower pain/function scores than male. Both males and females demonstrated significant raise $(\mathrm{p}<0.0001)$ in all KSS and SF12 components except for SF12 Mental component, in case of males. Schroer et al. and Nassif et al. reported comparable improvement in $\mathrm{KSS}$ and $\mathrm{KSS} /$ SF12, respectively for males and females $[16,17,19,20,29,30]$.

About the KSS/SF12 result comparison between males and females, it is better to differentiate $\Delta_{\text {scores }}$, as the preoperative scores were distinctive. The $\Delta_{\text {scores }}$ were higher for men than women significantly for KSS Knee (51.2 vs. 45.3, p=0.007), KSS function (26.7 vs. 22.8, $\mathrm{p}=0.015)$, and $\mathrm{SF} 12$ physical (14.2 vs. 13.2, $\mathrm{p}=0.004)$ scores, while higher SF12 Mental scores $(2.3$ vs. 0.3, $\mathrm{p}=0.027)$ were noted in women. Accordingly, statistical score improvement comparisons didn't demonstrate a reliable gender advantage.

The motion change post TKA is inversely proportional to preop value, i.e., patients with limited motion have tendency to increase post-surgery, whereas those with high level of motion at first tend to remain the same, or maybe lose a little amount of motion, post-surgery. Although, a possible gender effect has not been explored beforehand. During stratification of motion 
results by preoperative values, i.e., $<95^{\circ}, 95-105^{\circ}$, and $>105^{\circ}$, we discovered nearly similar $\Delta_{\mathrm{ROM}} / \Delta_{\mathrm{PF}}$ values for both male and female. No sexual orientation impact on motion was observed as a whole, or as a component of preoperative motion. Schroer et al. and Nassif et al. reported comparable $\Delta \mathrm{PF}$ values [20,23,29].

The survival analysis of KSS, SF12, ROM, and PF values propose comparable performance, in general, of this CR high flex knee in both male and female. Though there were some significant statistical contrasts in a few results between genders, these distinctions were little and were of the extent observed by others, who didn't attribute clinical significance to them [10-13,16-19]. In a study conducted in female patients by Zaki et al. [31], early clinical outcomes for knees with a gender-specific prosthesis were found to be similar to knees with a standard prosthesis there by showing no advantage of gender-specific knee prosthesis over standard unisex knee prosthesis with regards to early clinical outcomes. Genderspecific prosthesis didn't appear to confer any advantage in terms of clinician as well as patient-reported outcomes in study by Cheng et al. [32] for the female knee. In present study of 1,635 high flex knees, an aggregate of $8(0.49 \%)$ amendments were done, including four $(0.24 \%)$ for infection, three $(0.18 \%)$ for aseptic loosening, and one $(0.06 \%)$ for dislocation. No specific sequelae related with high flex knee configuration were obvious.

To begin with, the literature has for the most part inferred that standard/unisex knee outlines are similarly suitable for both genders. Secondly, our review filled a void in literature by contrasting the similar unisex/highflex knee outline in both genders, thus expanding the outcomes of others, while achieving similar conclusions. Thirdly, the full compatibility of whole range of femoral/tibial segment sizes of examined knee with each other might have permitted adequate scope to address patients' need irrespective of gender. That is to say, knee gender contrasts could be to a great extent addressed by implant size as opposed to implant outline contemplations.

Certain inherent limitations need to be considered during interpretation of the results as the study being a retrospective one. Despite this, the included population was high which might have diminished the limitation partially. This being a single-center study with restricted number of patients, the generalization of results should be made with care. Only single type of high flex knee was examined. In that capacity, these outcomes can't be specifically reached out to other high flex knee outlines. Just the mid-term survival analysis was outlined whereas long-term survival analysis of minimum $10 \mathrm{y}$ would be needed to completely report gender associated result contrasts that might exist with present knee outline.

\section{Conclusion}

It is critical that healthcare professionals have the important data accessible in making an informed decision regarding therapy options for patients. This is especially valid in jointreplacement as there are many implant varieties and design theories. The conflict that females have subordinate results post standard TKA, which is the main reason for gender specific outlines, has been dispersed by literature. We have additionally strengthened and expanded this status by demonstrating that a specific high flex knee configuration had similar clinical efficacy in both genders.

\section{References}

1. Dargel J, Michael JW, Feiser J, Ivo R, Koebke J. Human knee joint anatomy revisited: morphometry in the light of sex-specific total knee arthroplasty. J Arthroplasty 2011; 26: 346-353.

2. Greene KA. Gender-specific design in total knee arthroplasty. J Arthroplasty 2007; 22: 27-31.

3. Conley S, Rosenberg A, Crowninshield R. The female knee: anatomic variations. J Am Acad Orthop Surg 2007; 15: 31-36.

4. Woodland LH, Francis RS. Parameters and comparisons of the quadriceps angle of college-aged men and women in the supine and standing positions. Am J Sports Med 1992; 20: 208-211.

5. Guy SP, Farndon MA, Sidhom S, Al-Lami M, Bennett C, London NJ. Gender differences in distal femoral morphology and the role of gender specific implants in total knee replacement: a prospective clinical study. Knee 2012; 19: 28-31.

6. Hitt K, Shurman JR, Greene K, McCarthy J, Moskal J, Hoeman T, Mont MA. Anthropometric measurements of the human knee: correlation to the sizing of current knee arthroplasty systems. J Bone Joint Surg Am 2003; 85: 115-122.

7. Xie $X$, Lin L, Zhu B, Lu Y, Lin Z, Li Q. Will gender specific total knee arthroplasty be a better choice for women? A systematic review and meta-analysis. Eur J Orthop Surg Traumatol 2014; 24: 1341-1349.

8. von Roth P, Matziolis G, Pfitzner T, Mayr HO, Klein T, Preininger B, Winkler T, Hube R. Early results of genderspecific posterior stabilized total knee arthroplasty without patella resurfacing. Orthopade 2013; 42: 866-873.

9. Song EK, Park SJ, Yoon TR, Park KS, Seo HY, Seon JK. Hi-flexion and gender-specific designs fail to provide significant increases in range of motion during cruciateretaining total knee arthroplasty. J Arthroplasty 2012; 27: 1081-1084.

10. Thomsen MG, Husted H, Bencke J, Curtis D, Holm G, Troelsen A. Do we need a gender-specific total knee replacement? A randomised controlled trial comparing a highflex and a gender-specific posterior design. J Bone Joint Surg Br 2012; 94: 787-792.

11. Kim YH, Choi Y, Kim JS. Comparison of standard and gender-specific posterior-cruciate-retaining high-flexion total knee replacements: a prospective, randomized study. J Bone Joint Surg Br 2010; 92: 639-645.

12. Song EK, Jung WB, Yoon TR, Park KS, Seo HY, Seon JK. Comparison of outcomes after bilateral simultaneous total 
knee arthroplasty using gender-specific and unisex knees. J Arthroplasty 2012; 27: 226-231.

13. Singh H, Mittal V, Nadkarni B, Agarwal S, Gulati D. Gender-specific high-flexion knee prosthesis in Indian women: a prospective randomised study. J Orthop Surg (Hong Kong) 2012; 20: 153-156.

14. Tanavalee A, Rojpornpradit T, Khumrak S, Ngarmukos S. The early results of gender-specific total knee arthroplasty in Thai patients. Knee 2011; 18: 483-487.

15. Merchant AC, Arendt EA, Dye SF, Fredericson M, Grelsamer RP, Leadbetter WB, Post WR, Teitge RA. The female knee: anatomic variations and the female-specific total knee design. Clin Orthop Relat Res 2008; 466: 3059-3065.

16. Dalury DF, Mason JB, Murphy JA, Adams MJ. Analysis of the outcome in male and female patients using a unisex total knee replacement system. J Bone Joint Surg Br 2009; 91: 357-360.

17. MacDonald SJ, Charron KD, Bourne RB, Naudie DD, McCalden RW, Rorabeck CH. The John Insall award: gender-specific total knee replacement: prospectively collected clinical outcomes. Clin Orthop Relat Res 2008; 466: 2612-2616.

18. Muenzberg M, Stretz C, Baur W, Stangl R, Merschin D. Gender influence on the outcome of a unisex total knee arthroplasty system. Technol Health Care 2014; 22: 129-136.

19. Ritter MA, Wing JT, Berend ME, Davis KE, Meding JB. The clinical effect of gender on outcome of total knee arthroplasty. J Arthroplasty 2008; 23: 331-336.

20. Schroer WC, Stormont DM, Pietrzak WS. Seven-year survivorship and functional outcomes of the high-flexion Vanguard complete knee system. J Arthroplasty 2014; 29: 61-65.

21. Endres S, Wilke A. High flexion total knee arthroplastymid-term follow up of 5 years. Open Orthop J 2011; 5: 138-142.

22. Cho SD, Youm YS, Park KB. Three- to six-year follow-up results after high-flexion total knee arthroplasty: can we allow passive deep knee bending? Knee Surg Sports Traumatol Arthrosc 2011; 19: 899-903.

23. Stormont DM, Chillag KJ, Scott JW, Klaassen MA, Pietrzak WS. The relationship between pre- and postoperative range of motion utilizing three cruciateretaining total knee prostheses. J Invest Surg 2009; 22: 368-374.
24. Dorey F, Amstutz HC. Survivorship analysis in the evaluation of joint replacement. J Arthroplasty 1986; 1: 63-69.

25. Insall JN, Dorr LD, Scott RD, Scott WN. Rationale of the knee society clinical rating system. Clin Orthop Relat Res 1989; 248: 13-14.

26. Jenkinson C, Layte R, Jenkinson D, Lawrence K, Petersen S, Paice C, Stradling J. A shorter form health survey: can the SF-12 replicate results from the SF-36 in longitudinal studies? J Public Health Med 1997; 19: 179-186.

27. Chin KR, Dalury DF, Zurakowski D, Scott RD. Intraoperativemeasurements ofmale and female distal femurs during primary total knee arthroplasty. J Knee Surg 2002; 15: 213-217.

28. Kievit AJ, Schafroth MU, Blankevoort L, Sierevelt IN, van Dijk CN, van Geenen RC. Early experience with the Vanguard complete total knee system: 2-7 years of followup and risk factors for revision. J Arthroplasty 2014; 29: 348-354.

29. Nassif JM, Pietrzak WS. Clinical outcomes in men and women following total knee arthroplasty with a high-flex knee: no clinical effect of gender. Sci World J 2015; 2015: 285919.

30. Liebs TR, Herzberg W, Roth-Kroeger AM, Rüther W, Hassenpflug J. Women recover faster than men after standard knee arthroplasty. Clin Orthop Relat Res 2011; 469: 2855-2865.

31.Zaki EM, Elkhadrawe TA, Ebied AM, Elsayed AS, Saad HE. Comparison between standard and gender-specific knee designs in total knee arthroplasty in female patients. Am J Sports Sci 2015; 3: 67-72.

32. Cheng $\mathrm{T}$, Zhu C, Wang J, Cheng $\mathrm{M}$, Peng $\mathrm{X}$, Wang Q, Zhang X. No clinical benefit of gender-specific total knee arthroplasty. Acta Orthop 2014; 85: 415-421.

\section{*Correspondence to}

Xiaoqiang Zhuang

Department of Orthopaedics

The Affiliated National Hospital of Guangxi Medical University

PR China 